\title{
Erratum to: Encephalopathy and death in infants with abusive head trauma is due to hypoxic-ischemic injury following local brain trauma to vital brainstem centers
}

\author{
Jakob Matschke • Andreas Büttner • \\ Markus Bergmann • Christian Hagel • Klaus Püschel • \\ Markus Glatzel
}

Published online: 20 September 2014

(C) Springer-Verlag Berlin Heidelberg 2014

\section{Erratum to: Int J Legal Med}

DOI 10.1007/s00414-014-1060-7

Unfortunately, in the original version of this article initially published, in the results part under the heading "Case-control analysis of 20 AHT-victims with instant death with 20 SIDS victims" it was reported that:

"Logistic regression run separately for these two parameters adjusted for age, sex, and brain weight as possible confounding factors showed a significant effect for APP-positive

axons in the brainstem (odds ratio $[\mathrm{OR}]=3.5 ; 95 \%$ confidence interval $[\mathrm{CI}]=1.3$ to $9.2 ; p=0.010$ ) in the cerebellar peduncles $(\mathrm{OR}=1.3 ; 95 \% \mathrm{CI}=1.1$ to $1.7 ; p=0.012$; see Table 2 with complete original data in the online resource 3 ). Instead, this sentence should read:

"Logistic regression run separately for these two parameters adjusted for age, sex, and brain weight as possible confounding factors showed a significant effect for APP-positive axons in the brainstem (odds ratio $[\mathrm{OR}]=3.1 ; 95 \%$ confidence interval $[\mathrm{CI}]=1.2$ to $7.7 ; p=0.015$ ) in the cerebellar

The online version of the original article can be found at http://dx.doi.org/ 10.1007/s00414-014-1060-7.

J. Matschke $(\bowtie)$

Forensic Neuropathology Unit, University Medical Centre,

Hamburg-Eppendorf, 20246 Hamburg, Germany

e-mail: matschke@uke.de

J. Matschke $\cdot$ C. Hagel $\cdot$ M. Glatzel

Institute of Neuropathology, University Medical Centre,

Hamburg-Eppendorf, Hamburg, Germany

A. Büttner

Institute of Legal Medicine, Medical Faculty, University of Rostock,

Rostock, Germany

M. Bergmann

Institute of Clinical Neuropathology, Klinikum Bremen-Mitte,

Bremen, Germany

K. Püschel

Institute of Legal Medicine, University Medical Centre,

Hamburg-Eppendorf, Hamburg, Germany 
peduncles $(\mathrm{OR}=1.5 ; 95 \% \mathrm{CI}=0.9$ to $2.6 ; p=0.136$; see

Table 2 with complete original data in the online resource 3 ).
In addition, parts "c" and " $d$ " in Figure 2 were identical. The correct Figure 2 is given here. a

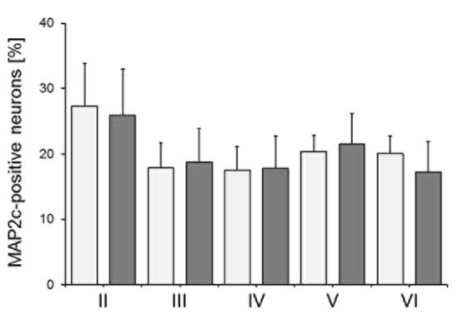

b

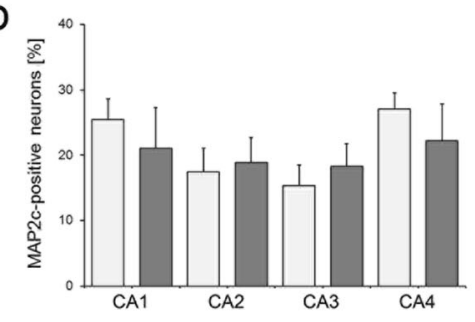

C

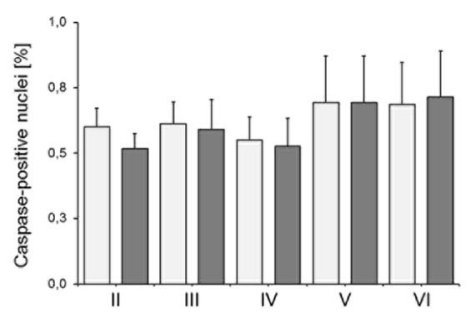

d

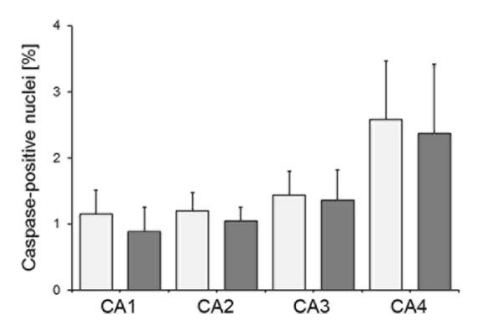

e

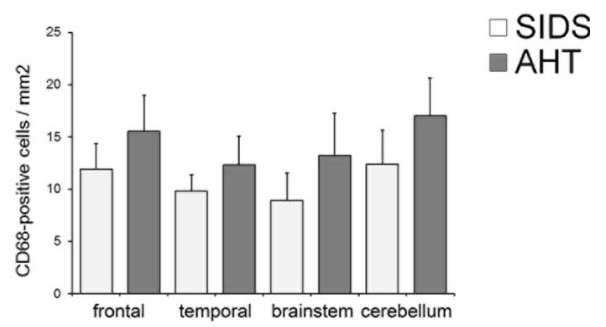

f

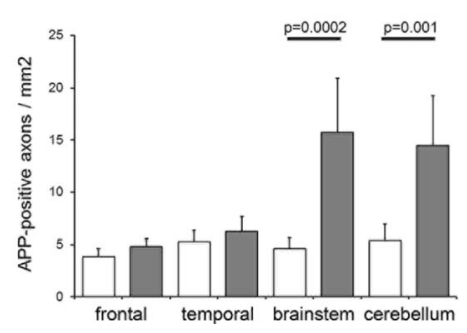

We regret this error; consequences for any of the results drawn in this study did not occur. 